\title{
Blood calprotectin in children with juvenile idiopathic arthritis: relationship to flare development after discontinuation of treatment
}

\author{
Yaryna Boyko ${ }^{1}$, Viktoriia Ivanova², Maryna Vakaruk ${ }^{3}$, Tamila Kozina ${ }^{4}$, Nataliia Shevchenko ${ }^{5}$, \\ Nataliia Vaizer ${ }^{6}$, Olha Synoverska ${ }^{7}$, Oksana Chubata $^{8}$, Olha Marchuk ${ }^{9}$, Anna Havrylyuk ${ }^{10}$ \\ 1Department of Pediatrics, Western-Ukrainian Specialized Children's Medical Centre, Lviv, Ukraine \\ ${ }^{2}$ Communal Non-profit Enterprise Regional Clinical Children's Hospital of Kirovohrad Regional Council, Kropyvnytskyi, Dnipropetrovsk \\ National Medical University, Kropyvnytskyi, Ukraine \\ ${ }^{3}$ Regional Children's Clinical Hospital, Odessa, Ukraine \\ 4"Medykgrup", Kherson, Ukraine \\ ${ }^{5}$ Institute of Healthcare of Children and Adolescents of the National Academy of Medical Sciences of Ukraine, Kharkiv, Ukraine \\ ${ }^{6}$ Mariupol Territorial Medical Association of Woman's and Child's Health, Ukraine \\ ${ }^{7}$ Ivano-Frankivsk National Medical University, Ukraine \\ ${ }^{8}$ Ternopil Regional Children's Hospital, Ukraine \\ 'Vinnytsia Regional Children's Clinical Hospital, Ukraine \\ ${ }^{10}$ Department of Clinical Immunology and Allergology, Danylo Halytsky Lviv National Medical University, Lviv, Ukraine
}

\begin{abstract}
Objectives: The study aim was to prospectively evaluate the relationship between disease flare development in children with juvenile idiopathic arthritis (JIA) after discontinuation of treatment and serum calprotectin levels (MRP8/14).

Material and methods: Determination of blood serum level of calprotectin was performed in 54 patients with inactive JIA from various regions of Ukraine. The inclusion criterion was the existence of an inactive state of the disease in children with JIA for at least 6 months. During 1 week after blood sampling for determination of serum calprotectin (MRP8/14) level the patients were completely discontinued of all therapy. Determination of calprotectin level in blood serum was performed with reagents EK-MRP8/14 Buhlmann (MRP8/14; S100A8/9), Switzerland, using the ELISA method.

Results: The trial results showed that 3 months after discontinuation of treatment in patients with inactive JIA, the flares developed in 5 out of 54 patients (9.3\%). The median calprotectin level before discontinuation of the treatment was $1,700 \mathrm{ng} / \mathrm{ml}$ in patients who developed a flare, and 1,500 ng/ml in other studied patients (not statistically significant). At 6 months, the flare had developed in an additional 3 out of 48 (6.3\%) of patients, who continued to be followed up, while their median calprotectin serum levels were $1,300 \mathrm{ng} / \mathrm{ml}$ and $1,500 \mathrm{ng} / \mathrm{ml}$ respectively (not statistically significant). At $12 \mathrm{months}$, the flares had developed in 13 more out of 45 (28.9\%) patients, who continued to be followed up, while the median calprotectin serum level in these patients before discontinuation of treatment was $1,100 \mathrm{ng} / \mathrm{ml}$ and $1,650 \mathrm{ng} / \mathrm{ml}$ respectively (not statistically significant).

Conclusion: After discontinuation of treatment a flare over the next year of follow-up developed in $38.9 \%$ of patients. The study results did not reveal a significant difference in calprotectin level in patients with JIA prior to complete discontinuation of treatment who developed a flare and those without a flare after 3, 6 and 12 months.
\end{abstract}

Key words: juvenile idiopathic arthritis, blood calprotectin, biomarkers, flare.

Address for correspondence:

Yaryna Boyko, Department of Pediatrics, Western-Ukrainian Specialized Children's Medical Centre, 27 Dnisterska St., 79035 Lviv, Ukraine, e-mail: jboyko@ukr.net

Submitted: 15.04.2020; Accepted: 15.07.2020 


\section{Introduction}

With up-to-date treatment most patients with juvenile idiopathic arthritis (JIA) reach the state of inactive disease and remission. After complete discontinuation of treatment, the flares of the disease develop only in a fraction of patients. Logically therefore a question arises: which patients with JIA can stop the treatment without having a flare of the disease in the future? It is important to verify those patients with JIA in remission, who will not develop disease flare after discontinuation of treatment. The decision regarding compete discontinuation of treatment today is based mainly on empirical experience of practicing pediatric rheumatologists. Thus, is it possible to predict the disease course after discontinuation of treatment? Are there biomarkers which could predict the possible flare of the disease? Several up-to-date laboratory markers reflect the subclinical activity of the disease [1-3].

These include MRP8/14, called blood calprotectin. Given that MRP8/14 reflects the subclinical activity of JA, this parameter can be used to monitor the treatment effectiveness, as well as prediction of the disease flare after discontinuation of treatment.

Numerous studies have shown that MRP8/14 may serve as an independent prediction marker of JIA flare risk after discontinuation of treatment [1, 2, 4-10].

The study aim is to prospectively evaluate the disease flare development in children with JIA after discontinuation of treatment and serum calprotectin levels (MRP8/14).

\section{Material and methods}

Determination of blood serum level of calprotectin was performed in 54 patients with inactive JIA from various regions of Ukraine (Lviv, Kropyvnytskyi, Ivano-Frankivsk, Odessa, Kherson, Kharkiv, Vinnytsia, Mariupol, and Ternopil). The JIA diagnosis was determined based on ILAR criteria, Durban, 1997, Edmonton, 2001 $[11,12]$.

The inactive disease state was determined according to Wallace criteria, 2011 [13]. The inclusion criterion was the existence of an inactive state of the disease in children with JIA for at least 6 months. During 1 week after blood sampling for determination of blood calprotectin (MRP8/14) level the patients were completely discontinued of all therapy. The blood serum samples were kept frozen until the time of investigations at minus $20^{\circ} \mathrm{C}$. Blood samples were transported frozen. Further follow-up of patients covered by this study continued for the next 12 months and included visits to a physician every three months with clinical and laboratory investigations. Calprotectin determination was performed at the first examination (B0) and 3 months after discontinuation of treatment (B1).

Determination of calprotectin level in blood serum was performed with reagents EK-MRP8/14 Buhlmann (MRP8/14; S100A8/9), Switzerland, using the ELISA method. The analysis was performed in the laboratory of Communal Non-profit Enterprise of Lviv Regional Council "Western-Ukrainian Specialized Children's Medical Centre".

Statistical processing of data was performed using the STATISTIC 8.0 software package. Distribution of quantitative parameters in the group is represented as median (minimum-maximum) [lower-upper quartiles], given that the distribution of parametric parameters in the sampling was non-Gaussian (in the Shapiro-Wilk test). The comparison of rank and parametric parameters was performed according to Mann-Whitney criteria, which do not require testing for normal distribution and are acceptable for comparison of small sample groups.

\section{Results}

A 54 patients with JIA from 9 Ukrainian pediatric rheumatology centers were enrolled in the study. Median age for these patients was 8.6 years, with median disease duration being 36 months. Patients of female gender prevailed (68.5\%). All patients were in the state of inactive disease, the median of which was 11 months, with the minimal duration of inactive disease being 6 months.

Patients with all types of the disease course were enrolled in the study, among whom patients with oligoarthritis prevailed (59.3\%); $22.2 \%$ of patients had polyarticular JIA, and the rest in equal degree (9.3\%) were distributed between patients with systemic JIA and enthesitis-related arthritis. The majority of patients (88.9\%) received background monotherapy with methotrexate; three patients were prescribed methotrexate together with biological agents (tocilizumab in one case, adalimumab in another, and etanercept in the third), one patient received etanercept, and one other received sulfasalazine.

Median calprotectin level in all patients with JIA who had an inactive form of the disease before complete discontinuation of the treatment was 1,550 (200-30,000) $\mathrm{ng} / \mathrm{ml}$, and in patients treated in the past with methotrexate only 1,450 (200-30,000) ng/ml (Table I). Our study assessed the possible dependency of calprotectin level in patients with inactive JIA disease on the type of the disease (Table II), duration of inactive disease up until the moment of discontinuation of treatment, the child's age (before and after 5 years), and overall duration of the disease until the moment of discontinuation of treatment. 
Table I. Features of juvenile idiopathic arthritis (JIA) patients enrolled in the study

\begin{tabular}{|c|c|}
\hline Features & Value \\
\hline Total number of subjects & 54 \\
\hline $\begin{array}{l}\text { Age at time of the study, years, } \\
\text { median (min-max) }\end{array}$ & $8.6(1.8-18.6)$ \\
\hline $\begin{array}{l}\text { Age of JIA onset, years, median } \\
\text { (min-max) }\end{array}$ & $3.7(1.1-17.0)$ \\
\hline \multicolumn{2}{|l|}{ Gender, number of subjects (\%) } \\
\hline Females & $37(68.5)$ \\
\hline Males & $17(31.5)$ \\
\hline $\begin{array}{l}\text { Disease duration, months, } \\
\text { median (min-max) }\end{array}$ & $36.0(10.0-180.0)$ \\
\hline $\begin{array}{l}\text { Inactive disease duration, months, } \\
\text { median (min-max) }\end{array}$ & $11.0(6.0-36.0)$ \\
\hline \multicolumn{2}{|l|}{ JIA disease type, number of subjects } \\
\hline Systemic & 5 \\
\hline Polyarthritis & 12 \\
\hline Oligoarthritis & 32 \\
\hline Enthesitis-related arthritis & 5 \\
\hline \multicolumn{2}{|l|}{ Inactive disease criteria } \\
\hline Systemic signs, absent/present & $54 / 0$ \\
\hline Arthritides, absent/present & $54 / 0$ \\
\hline ESR, mm/h, median (min-max) & $5(2-20)$ \\
\hline Uveitis, absent/present & $54 / 0$ \\
\hline VAS, score, median (min-max) & $0(0-1)$ \\
\hline JADAS27, score, median (min-max) & $0(0-1)$ \\
\hline CHAQ, median (min-max) & $0(0-0)$ \\
\hline \multicolumn{2}{|l|}{$\begin{array}{l}\text { Therapy on which an inactive disease } \\
\text { state was achieved }\end{array}$} \\
\hline Methotrexate & 48 \\
\hline Methotrexate, etanercept & 1 \\
\hline Methotrexate, adalimumab & 1 \\
\hline Methotrexate, tocilizumab & 1 \\
\hline Methotrexate, Delagil & 1 \\
\hline Sulfasalazine & 1 \\
\hline Etanercept & 1 \\
\hline $\begin{array}{l}\text { Blood calprotectin, ng/ml, median } \\
\text { (min-max) }\end{array}$ & $\begin{array}{c}1,550 \\
(200-30,000)\end{array}$ \\
\hline $\begin{array}{l}\text { Blood calprotectin, } \mathrm{ng} / \mathrm{ml} \text {, median } \\
(\min -\max )^{*}\end{array}$ & $\begin{array}{c}1,450 \\
(200-30,000)\end{array}$ \\
\hline
\end{tabular}

The study results showed that in patients with JIA who have clinical signs of inactive disease, the median calprotectin level is determined at the level between $600 \mathrm{ng} / \mathrm{ml}$ (enthesis-arthritis), 1,400 ng/ml (oligoarthritis), $1,800 \mathrm{ng} / \mathrm{ml}$ (polyarthritis), and up to $3,200 \mathrm{ng} / \mathrm{ml}$ (systemic arthritis), but no significant differences in blood calprotectin level were found between patients with different types of JIA (Table II). In particular, no statistically significant difference was found between the level of blood calprotectin and duration of the inactive disease: 6 months, 6-12 months, and 12 and more months.

Median blood calprotectin level in patients with inactive JIA of 6 months duration was $1,900 \mathrm{ng} / \mathrm{ml}$, of 6 to 12 months duration - 1,150 ng/ml, and over 12 months duration - 1,550 ng/ml. Median blood calprotectin level in patients with inactive JIA disease up to 5 years of age was $1,650 \mathrm{ng} / \mathrm{ml}$, and in patients over 5 years of age $-1,450 \mathrm{ng} / \mathrm{ml}$. Median blood calprotectin level in patients with inactive JIA who had disease duration up to 24 months was $1,200 \mathrm{ng} / \mathrm{ml}$, and over 24 months $1,600 \mathrm{ng} / \mathrm{ml}$, the difference being not statistically significant too.

At 3 months, data regarding 54 patients were obtained, and it was found that 5 of them (9.3\%) developed a flare of JIA (Table III). Median calprotectin level in patients with JIA 3 months after discontinuation of treatment was $800 \mathrm{ng} / \mathrm{ml}$. Comparison of blood calprotectin levels before discontinuation of treatment in patients with JIA who developed a flare 3 months after discontinuation of treatment (5 patients) and those without a flare (49 patients) was performed. No statistically significant difference in these parameters was found, their median calprotectin levels being 1,500 ng/ $\mathrm{ml}$ and $1,700 \mathrm{ng} / \mathrm{ml}$ respectively.

At 6 months, exacerbation was seen already in 8 patients (14.8\%). Similarly to the above results, no statistically significant difference in calprotectin levels prior to discontinuation of treatment was found between JIA patients who developed and those who did not develop flares, median calprotectin level being equally $1,500 \mathrm{ng} / \mathrm{ml}$ in each group (Table III).

At 12 months, the flares had developed already in 21 subjects (39.6\%). Calprotectin level prior to discontinuation of treatment in JIA patients with a flare was 1,300 ng/ml, and without a flare $-1,650 \mathrm{ng} / \mathrm{ml}$ (Table III).

Thus, it was established that in 3 months the flare of the disease developed in 5 out of 54 patients (9.3\%) (Table IV). Median calprotectin level before discontinuation of treatment was $1,700 \mathrm{ng} / \mathrm{ml}$, and in patients who did not develop a flare $-1,500 \mathrm{ng} / \mathrm{ml}$. One patient (a girl) dropped out of the study at 3 months. At 6 months, the flares had developed in an additional 3 out of 48 patients (6.3\%), who continued participation in the study, median calprotectin level being $1,300 \mathrm{ng} / \mathrm{ml}$ and $1,500 \mathrm{ng} / \mathrm{ml}$ respectively.

At 12 months, the flares had developed in an additional 13 out of 45 patients (28.9\%), who continued to be followed up by pediatric rheumatologists, median calprotectin level in these patients before discontinu- 
Table II. Blood calprotectin level in patients with different disease types of juvenile idiopathic arthritis (JIA) prior to discontinuation of treatment

\begin{tabular}{|c|c|c|c|}
\hline Disease type & $\begin{array}{l}\text { Number } \\
\text { of patients }\end{array}$ & $\begin{array}{l}\text { Calprotectin level, ng/ml, } \\
\text { median (min-max) }\end{array}$ & $\begin{array}{c}p \\
\text { (Mann-Whitney criteria) }\end{array}$ \\
\hline Oligoarthritis & 32 & $1,400(200-30,000)$ & \multirow{4}{*}{$\begin{array}{l}p^{12}=0.54 \\
p^{13}=0.09 \\
p^{14}=0.67 \\
p^{22}=0.21 \\
p^{23}=0.92 \\
p^{34}=0.40\end{array}$} \\
\hline Polyarthritis & 12 & $1,800(200-11,200)$ & \\
\hline Systemic arthritis & 5 & $3,200(500-22,600)$ & \\
\hline Enthesitis-related arthritis & 5 & $600(400-24,000)$ & \\
\hline
\end{tabular}

$p^{12}$ - compared to patients with oligoarthritis and polyarthritis, $p^{13}$-compared to patients with oligoarthritis and systemic arthritis, $p^{14}$ - compared to patients with oligoarthritis and enthesitis-related arthritis, $p^{22}$ - compared to patients with polyarthritis and systemic arthritis, $p^{23}$ - compared to patients with polyarthritis and enthesitis-related arthritis, $p^{34}$ - compared to patients with systemic arthritis and enthesitis-related arthritis.

Table III. Study of links between blood calprotectin level in patients with juvenile idiopathic arthritis (JIA) prior to discontinuation of treatment and flare risk

\begin{tabular}{|c|c|c|c|c|c|}
\hline \multirow[t]{2}{*}{ Follow-up } & \multirow[t]{2}{*}{ Total } & \multirow[t]{2}{*}{$\begin{array}{c}\text { Gender } \\
\text { (male/female) }\end{array}$} & \multirow[t]{2}{*}{$\begin{array}{l}\text { Flare development, } \\
\text { number (abs., \%) }\end{array}$} & \multicolumn{2}{|c|}{$\begin{array}{l}\text { Calprotectin level in patients with JIA at visit } 0 \\
\text { (ng/ml, median [min-max]), who }\end{array}$} \\
\hline & & & & Developed a flare & Did not develop a flare \\
\hline \multirow[t]{2}{*}{ At 3 months } & 54 & $17 / 37$ & $5(9.3 \%)$ & $\begin{array}{c}1,700 \\
(920-24,000)\end{array}$ & $1,500(200-30,000)$ \\
\hline & & & & \multicolumn{2}{|c|}{$p^{\star \star}=0.35$} \\
\hline \multirow[t]{2}{*}{ At 6 months } & $53^{*}$ & $17 / 36^{*}$ & $8(15.1 \%)$ & $\begin{array}{c}1,500 \\
(200-30,000)\end{array}$ & $1,500(200-30,000)$ \\
\hline & & & & \multicolumn{2}{|c|}{$p^{\star \star}=0.619$} \\
\hline At 12 months & $53^{*}$ & $17 / 36^{*}$ & $21(39.6 \%)$ & $1,300(200-30,000)$ & $1,650(200-11,200)$ \\
\hline
\end{tabular}

* One patient withdrew from the study at 3 months, ${ }^{* *}$ Mann-Whitney criteria.

Table IV. Study of links between blood calprotectin level in patients with juvenile idiopathic arthritis (JIA) prior to discontinuation of treatment and flare risk

\begin{tabular}{|c|c|c|c|}
\hline \multirow{2}{*}{$\begin{array}{l}\text { Follow-up, } \\
\text { flares/in total } \\
\text { (\% of flares) }\end{array}$} & \multicolumn{2}{|c|}{$\begin{array}{l}\text { Calprotectin in patients with } J \mathrm{~A} \text { at visit } 0, \mathrm{ng} / \mathrm{ml} \text {, median } \\
\qquad(\text { min-max })\end{array}$} & \multirow[t]{2}{*}{$\begin{array}{c}p \\
\text { (Mann-Whitney criteria) }\end{array}$} \\
\hline & Flares & No flares & \\
\hline $\begin{array}{l}\text { At } 3 \text { months } \\
n=5 / 54(9.3 \%)\end{array}$ & $1,700(920-24,000)$ & $1,500(200-30,000)$ & 0.35 \\
\hline $\begin{array}{l}\text { At } 6 \text { months } \\
n=3 / 48^{*}(6.3 \%)\end{array}$ & $1,300(600-1,900)$ & $1,500(200-30,000)$ & 0.70 \\
\hline $\begin{array}{l}\text { In } 12 \text { months } \\
n=13 / 45(28.9 \%)\end{array}$ & $1,100(200-30,000)$ & $1,650(200-11,200)$ & 0.16 \\
\hline
\end{tabular}

ation of treatment being $1,100 \mathrm{ng} / \mathrm{ml}$ and $1,650 \mathrm{ng} / \mathrm{ml}$ respectively.

\section{Discussion}

In the last years blood calprotectin (MRP8/14) has been extensively studied as a potential biomarker of disease activity and treatment response in rheumatic and other inflammatory diseases. A direct correlation was found between blood calprotectin level and JADAS 27 activity score, ESR and CRP in patients with JIA [14]. In patients with enthesitis-related arthritis a correlation was found between the MRP8/14 levels and disease activity [4].

The blood calprotectin level is currently regarded as a verification marker for diagnostics of systemic JIA (s)IA), as it enables differential diagnostics with many diseases accompanied by a fever. In the study by Frosch 
[15] for the first time it was shown that serum calprotectin level statistically significantly increases in patients with active SIIA (from 14,920 $\pm 4,030 \mathrm{ng} / \mathrm{ml}$ ) as compared with healthy children of the control group, and patients with leukemia and infectious diseases.

The results of the study that we performed in the past have shown that blood calprotectin level was higher in patients with a systemic disease course (median $13,800 \mathrm{ng} / \mathrm{ml}$ ) and statistically significantly differed from the parameters in healthy children (median 1,800 ng/ml), patients with articular forms of JIA (median 2,700 ng/ml), patients with polyarthritis with negative RF (median $3,800 \mathrm{ng} / \mathrm{ml}$ ), and oligoarthritis (median 2,500 $\mathrm{ng} / \mathrm{ml}$ ). The highest calprotectin levels were found in patients with newly diagnosed SIIA, median being 32,500 ng/ml (from 13,800 to $177,000 \mathrm{ng} / \mathrm{ml}$ ) [14]. The role of blood calprotectin (MRP8/14) for diagnostics of systemic JIA $(s) \mid A)$ is confirmed by many studies; therefore blood calprotectin (MRP8/14) level is currently a widely recognized biomarker used to confirm the diagnosis of SJIA $[15,16]$.

It was shown that in patients with rheumatoid arthritis (RA) MRP8/14 is a strong predictor of response to biological treatment [5]. Another MRP8/14 study established that this parameter helps to predict the therapeutic response to treatment with methotrexate within the heterogeneous group of patients with JIA [6]. The results of this study enable the information about MRP8/14 level to be used for clarifying the issue of which patient will be a responder to methotrexate treatment, and which one will be better off with earlier introduction of biological therapy.

Studies of blood calprotectin level in patients with JIA have shown that its level was higher compared to the level in healthy controls, and higher in patients who had an active disease in comparison with patients in the remission status of JIA, being 9,600 $(100-48,610) \mathrm{ng} / \mathrm{ml}$ and 2,965 $(0-45,390) \mathrm{ng} / \mathrm{ml}$ respectively [1].

Because of the proven role of blood calprotectin (MRP8/14) as a sensitive biomarker of subclinical activity in patients with JIA, and because its level statistically significantly differs in JIA patients with active disease and in the remission period, results of its determination have started to be used for prediction of disease relapse after discontinuation of treatment - as an instrument for JIA disease course prediction.

The prognostic value of MRP8/14 regarding risk of relapse development in patients with JIA, who had clinical remission for at least one year after discontinuation of methotrexate treatment, is reflected in a number of studies. The prognostic role of blood calprotectin was first declared in the study by Foell et al. [7]. Obtained results have shown that MRP8/14 level above $250 \mathrm{ng} / \mathrm{ml}$ statistically significantly predicted risk of JIA relapse [7].
The same authors hypothesized that three biomarkers (S100A12, MRP8/14, and hsCRP) can serve as predictors of flare development after discontinuation of treatment in patients with JIA. This study has shown that MRP8/14 may serve as an independent prediction marker of JIA flare risk after discontinuation of treatment. Upon comparison of patients who were in the state of stable remission and patients with JIA who developed a flare within 6 months after discontinuation of treatment, the median MRP8/14 level was $440 \mathrm{ng} / \mathrm{ml}$ and $850 \mathrm{ng} / \mathrm{ml}$ respectively [2].

The link between the MRP8/14 level and the disease flare after discontinuation of etanercept was studied. Patients who experienced a flare of the disease within 6 months after discontinuation of etanercept had a higher blood calprotectin level in the period of discontinuation of treatment than patients without a flare, the median blood calprotectin level being 1,025 ng/ml and $505 \mathrm{ng} /$ $\mathrm{ml}$ respectively [8].

Similar results regarding prediction of the SJIA flare were obtained in the study of Holzinger et al. [9], who proved that high MRP8/14 levels predict flares in patients with systemic-onset JIA. In patients with sJIA the MRP8/14 level above $740 \mathrm{ng} / \mathrm{ml}$ during clinical remission accurately predicted a flare of systemic JIA [9].

The results obtained in our study differ from the results obtained by our colleagues. We did not find a significant difference in blood calprotectin levels in those patients with JIA prior to complete discontinuation of treatment who developed a flare, and without a flare after 3, 6 and 12 months. So, why do the results obtained by us completely differ from the published data?

Our results showed substantially lower blood calprotectin levels in patients with JIA who are in the state of inactive disease, compared to data obtained by us in past studies regarding its level in the period of an active disease. However, despite this difference, it appeared that these low levels cannot predict a future flare of the disease. Maybe the calprotectin level could predict a future flare in patients with sJIA only. These speculations are based on correlation of the pathogenesis of systemic JIA (autoinflammatory) and the origin of calprotectin (MRP8/14), which is produced by monocytes and reflects activation of the inborn immunity mechanisms - a basis of sJIA pathogenesis. In our opinion, further studies should be performed with regard to flare risk prediction that would engage patients with systemic arthritis only.

However, our results are consistent with data of the study published in 2019 which investigated the predictive role of blood calprotectin prior to discontinuation of treatment with TNF inhibitors in 137 patients with polyarticular-course JIA. No correlation was found between time to relapse of the disease and blood calprotectin 
(MRP8/14) level prior to discontinuation of anti-TNF therapy [10]. The authors of this study tried to answer the question why in their study blood calprotectin had a limited role for prediction of disease flare. An issue of possible presence of infectious disease in the study subjects with JIA that could influence the basal blood calprotectin (MRP8/14) level was considered. However, the main explanation, from the authors' viewpoint, lay in the clearance of biological preparation which these patients received, influencing the investigated biological marker. This study was related to patients on biological therapy with TNF inhibitors, which is different from the patients enrolled in our study.

Further studies of biomarkers that could predict flares in patients with JIA would be important. These could be studies of blood calprotectin in homogeneous groups of patients, particularly those with systemic JA. It is likely that analysis of combined biomarkers (clinical, laboratory, and instrumental) would be more worthwhile in the sense of development of biomarkers that would predict JIA flares in children after complete discontinuation of treatment.

\section{Conclusions}

After discontinuation of treatment a flare over the next year of follow-up develops in $38.9 \%$ of patients with inactive JIA. The study results did not reveal a significant difference in blood calprotectin levels in those patients with JIA prior to complete discontinuation of treatment who developed a flare and without a flare after 3, 6 and 12 months. Given that the group of JIA patients enrolled in this study was small, it would be reasonable to continue to study the value of blood calprotectin level as a prognostic biomarker in a larger cohort of patients.

The authors declare no conflict of interest.

\section{References}

1. Gohar F, Husmann E, Haas PJ, et al. PReS-FINAL-2216: Biomarkers MRP8/14 and S100A12 correspond with flare and remission clinical status in Sojia patients in the AID-NET register. Pediatr Rheumatol Online J 2013; 11 (Suppl 2): 206, DOI: 10.1186/1546-0096-11-S2-P206.

2. Gerss J, Roth J, Holzinger D, et al. Phagocyte-specific S100 proteins and high-sensitivity $\mathrm{C}$ reactive protein as biomarkers for a risk-adapted treatment to maintain remission in juvenile idiopathic arthritis: a comparative study. Ann Rheum Dis 2012; 71: 1991-1997, DOI: 10.1136/annrheumdis-2012-201329.

3. Orczyk K, Smolewska E. A Granulocyte-Specific Protein S100A12 as a Potential Prognostic Factor Affecting Aggressiveness of Therapy in Patients with Juvenile Idiopathic Arthritis. J Immunol Res 2018; 2018: 5349837, DOI: 10.1155/2018/5349837.
4. Rahman MT, Myles A, Gaur P, et al. TLR4 endogenous ligand MRP8/14 level in enthesitis-related arthritis and its association with disease activity and TLR4 expression. Rheumatology (Oxford) 2014; 53: 270-274, DOI: 10.1093/rheumatology/ ket375.

5. Choi IY, Gerlag DM, Herenius MJ, et al. MRP8/14 serum levels as a strong predictor of response to biological treatments in patients with rheumatoid arthritis. Ann Rheum Dis 2015; 74: 499-505, DOI: 10.1136/annrheumdis-2013-203923.

6. Moncrieffe H, Ursu S, Holzinger D, et al. A subgroup of juvenile idiopathic arthritis patients who respond well to methotrexate are identified by the serum biomarker MRP8/14 protein. Rheumatology (Oxford) 2013; 52: 1467-1476, DOI: 10.1093/ rheumatology/ket152.

7. Foell D, Frosch $M$, Schulze zur Wiesch A, et al. Methotrexate treatment in juvenile idiopathic arthritis: when is the right time to stop? Ann Rheum Dis 2004; 63: 206-208, DOI: 10.1136/ard.2003.005686.

8. Anink J, Van Suijlekom-Smit LWA, Otten MH, et al. MRP8/14 serum levels as a predictor of response to starting and stopping anti-TNF treatment in juvenile idiopathic arthritis. Arthritis Res Ther 2015; 17: 200.

9. Holzinger D, Frosch M, Kastrup A, et al. The Toll-like receptor 4 agonist MRP8/14 protein complex is a sensitive indicator for disease activity and predicts relapses in systemic-onset juvenile idiopathic arthritis. Ann Rheum Dis 2012; 71: 974-980, DOI: 10.1136/annrheumdis-2011-200598.

10. Hinze CH, Foell D, Johnson AL, et al. Serum S100A8/A9 and S100A12 Levels in Children with Polyarticular Forms of Juvenile Idiopathic Arthritis: Relationship to Maintenance of Clinical Inactive Disease During and Flare after Discontinuation of Anti-TNF Therapy. Arthritis Rheum 2019; 71: 451-459, DOI: 10.1002/art.40727.

11. Petty RE, Southwood TR, Baum J, et al. Revision of the proposed classification criteria for juvenile idiopathic arthritis: Durban. J Rheumatol 1998; 25:1991-1994.

12. Petty RE, Southwood TR, Manners PS, et al. International League of Associations for Rheumatology classification of juvenile idiopathic arthritis, second revision, Edmonton, 2001. J Rheumatol 2004; 31: 390-392.

13. Wallace CA, Giannini EH, Huang B, et al. American College of Rheumatology provisional criteria for defining clinical inactive disease in select categories of juvenile idiopathic arthritis. Arthritis Care Res (Hoboken) 2011; 63: 929-936, DOI: 10.1002/ acr.20497.

14. Boyko JJ. Diagnostic and Predictive Role of Blood Calprotectin (MRP8/MRP14) in Patients with Different Forms of Juvenile Idiopathic Arthritis. Zdorovie rebionka [Health of a Child] 2016; 7: 18-24.

15. Frosch M, Ahlmann M, Vogl T, et al. The myeloid-related proteins 8 and 14 complex, a novel ligand of Toll-like receptor 4 , and interleukin-1 $\beta$ form a positive feedback mechanism in systemic-onset juvenile idiopathic arthritis. Arthritis Rheum 2009; 60: 883-891, DOI: 10.1002/art.24349

16. Boyko J. Measurement of blood calprotectin (MRP-8/MRP-14) levels in patients with juvenile idiopathic arthritis. Reumatologia 2017; 55: 10-14, DOI: 10.5114/reum.2017.66682. 